\title{
REFLEXÕES SOBRE RELAÇÕES DE PODER NA PRÁTICA DE ENFERMAGEM
}

\author{
I sabela Silva Câncio VELL OSO ${ }^{a}$, Christine $\mathrm{CECI}^{\mathrm{b}}$, M arília ALVES ${ }^{\mathrm{c}}$
}

\section{RESUMO}

U ma reflexão sobre relações de poder na prática de enfermagem envolve aspectos das práticas cotidianas da equipe de enfer magem e da subjetividade dos sujeitos nel as envolvidos. A prática de enfer magem é muito mais do que uma prática em si. Assume a dimensão do significado atribuído pelos diferentes sujeitos que interagem em seus diversos cenários. Propõe-se, aqui, uma r reflexão sobre as relações de poder na prática de enfermagem, considerando sua complexidade, os múltiplos processos que as constituem e as circunstâncias que determinam as for mas de se pensar e de se agir em relação a el as. Para isso, é preciso pensar a subjetividade do sujeito, considerando-se como os limites profissionais são estabel ecidos e mantidos e quais são os efeitos dessas relações para os sujeitos envolvidos, uma vez que relações de poder são definidas em transformações contínuas.

Descritores: Prática profissional. Relações interpessoais. Cuidados de enfer magem.

\section{RESUMEN}

U na reflexión sobre las relaciones de poder en las prácticas de enfermería envuelve cuestiones relativas a las prácticas cotidianas del equipo de enfermería, y la subjetividad de los individuos partici pantes de ellas. L a práctica de enfermería es mucho más de que una prática, pues incor poram la dimensión del significado atribuído por distintos sujetos que se integran en los diversos escenários donde suceden. Se propone aquí uma reflexión sobre las relaciones de poder en la práctica de enfermería teniendo em vista de su complejidad, los procesos del múltiplo que las constituyan y las circunstancias que determinan las formas de piensar y actuar en relación a ellas. Para esto, hay que pensar la subjetividad del sujeto, teniendo en cuenta como se establ ecen y se mantienen los límites profesionales, y cuáles son los efectos de estas relaciones para los sujetos implicados, ya que las relaciones de poder son determinadas por continuas transformaciones.

Descriptores: $\mathrm{P}$ rática profesional. $R$ elaciones inter per sonales. A tención de enfermagem.

Título: R eflexiones sobre relaciones de poder en la práctica de enfermería.

\section{ABSTRACT}

R eflections on pow er relations in nursing practice involves questions related to the daily practice of nursing staff as well the subjectivity of those involved in them. $\mathrm{N}$ ursing practice is morethan a practice in itself. It assumes the dimension of meaning ascribed to it by different subjects who interact in the places wher ethe practice takes place. We proposea reflection about pow er relations in nursing practice, considering their complexity, the many processes that constitute them and the circumstances that determine the ways of thinking about and acting in relation to them. Such reflection implies to think about the subject's subjectivity, the way professional boundaries areestablished, and the effects of theserelations upon the subjects involved, since pow er relations are in continuous transformations.

Descriptors: P rofessional practice Inter personal relations. N ursing care Title: R eflections about power relations in nursing practice.

\footnotetext{
a M estre em Enfermagem, D outoranda do Programa de Pós-G raduação em Enfermagem da U niversidade Federal de M inas G erais (U F M G), Belo H orizonte, $\mathrm{M}$ inas $\mathrm{G}$ erais, Brasil.

${ }^{b}$ D outora em Enfermagem, Professora A ssistente da E scola de Enfermagem da U niver sidade de A lberta, na Província de E dmonton, Canadá.

c D outora em Enfermagem, Professora T itular da Escola de Enfermagem da U F M G, Belo Horizonte, M inas G erais, Brasil.
} 


\section{INT RODUÇÃO}

A proposta de uma reflexão sobre relações de poder na prática de enfermagem pode parecer, em um primeiro momento, limitada a situações específicas de nosso cotidiano de trabal ho como, por exemplo, relações enfermeiro-médico, enfermeiropaciente, enfermeiro-equipe. E ntr etanto, tomando como base estudos sobre relações de poder de autores pós-estrutural istas, percebe-se que as discussões que envolvem essas relações são bastante complexas e per passam as práticas profissionais e a subjetividade dos sujeitos nelas envolvidos.

Práticas podem ser compreendidas como os lugares onde o que é dito e o que é feito, regras impostas e razões al egadas, o que é planejado e o que se admite se encontram e se interconectam. $\mathrm{Na}$ verdade, as práticas têm sua própria 'razão', são organizadas a partir de determinadas for mas de racionalidade, considerando determinados códigos de conhecimento e regras de conduta que delineiam sua forma e Ihes conferem inteligibilidade e acessibilidade, ao mesmo tempo em que organizam os princípios e as estratégias que as justificam ${ }^{(1)}$.

No contexto das práticas de enfermagem, compreender sua forma de organização e sua razão significa compreender muito mais do que as práticas de enfermagem em si, mas assume a dimensão de dar significado a diferentes sujeitos individuais e coletivos - que se inter conectam nos diversos cenários onde atuam os profissionais de saúde. É nesse sentido que a análise das práticas requer que se compreenda a organização do poder e do conhecimento em determinado contexto e que se estabeleça sua relação com os diversos dispositivos sociais, políticos e econômicos em questão. A nalisar as práticas auxilia a compreender, tanto como os arranjos são estabelecidos, quanto como são admitidos e aceitos em um determinado momento ${ }^{(2)}$.

A ssim, compreender a organização das relações de poder vivenciadas pelas equipes de enfermagem em sua prática profissional e os efeitos dos arranjos estabelecidos em suas práticas cotidianas exige que se considere a natureza do poder, do conhecimento e da subjetividade dos sujeitos envolvidos nos processos. N esse tipo de análise, é preciso considerar como o poder é exercido, como os limites profissionais são estabelecidos e mantidos e quais são os efeitos dessas relações para esses sujeitos $^{(3)}$. 0 que se propõe, neste artigo, é uma re- flexão sobre as relações de poder na prática de enfermagem, considerando sua complexidade, os múltiplos processos que as constituem e as circunstâncias que determinam as formas de se pensar e de se agir em relação a elas.

\section{CONSTITUIÇÃO DA SUBJ ETIVIDADE A PARTIR DA RELAÇÃO PODER/ SABER}

A subjetividade está intrinsecamente relacionada a questões sobre quem nós pensamos ser e como essas ideias sobre nós mesmos são constituídas. Isto é, formas de subjetividade são constituídas, historicamente, por meio de práticas heterogêneas que moldam os indivíduos de múltiplas maneiras. M ais do que relacionadas a como o indivíduo é constituído, as formas de subjetividade são uma expressão de como, por meio das relações do poder e do conhecimento, o sujeito se relaciona com o mundo. I sso envolve uma troca de conhecimento contínua, de forma que o indivíduo se torna, ao mesmo tempo, sujeito e objeto do conhecimento(4). É a sua condição de sujeito que detém o conhecimento em determinada situação que Ihe confere sua posição na relação estabelecida. A menção ao conhecimento, aqui, não se refere, restritamente, ao conhecimento científico, mas a todo tipo de conhecimento envolvido em cada prática consider ada.

$N$ essa perspectiva, o conhecimento muda de acordo com as condições históricas que estão relacionadas a relações de força e de poder. A o estabelecer a historicidade do conhecimento, considera-se que seja nula a possibilidade de neutralidade na produção do conhecimento, uma vez que a historicidade desvela a relação entre sistemas para a produção do conhecimento e, nesse sentido, os sistemas para o desenvolvimento de poder e de força. O u seja, o conhecimento não é meramente descoberto, não está al heio às relações de poder. Ele é produzido a partir de constantes esforços em uma luta para se estabel ecer um conhecimento, ou verdade, em particular, o que faz com que o poder e 0 conhecimento sejam considerados em uma relação binária de poder/ saber ${ }^{(5)}$.

No cenário das práticas de saúde, na sociedade atual, pode-se considerar que há uma transformação do significado de saúde, com uma complexidade que envolve aspectos políticos e sociais, além do mero padrão de normalidade fisiológica. Entretanto, o conceito de normalidade traz consigo uma relação de poder entre o conhecimento científico, a 
partir do qual é possível estabelecer parâmetros objetivos de definição de normalidade e a assistência à saúde propriamente dita. N essa relação, quem detém o conhecimento assume uma posição diferenciada, por ser responsável pela determinação de ações de cuidado à saúde( ${ }^{(6)}$. I sso evidencia a contingência do conhecimento, que é mediado pelas condições que o rodeiam e que necessariamente são constituídas num jogo de forças e poder ${ }^{(5)}$.

Ao longo da trajetória histórica da enfermagem, diferentes práticas sociais e profissionais constituíram e constituem uma série de subjetividades, com variadas interpretações. I sso sugere que o profissional de saúde pode assumir várias formas de subjetividade que podem se transformar, dinamicamente, à medida que as diversas práticas se desenvolvem, o que leva ao redimensionamento constante das relações de poder estabel ecidas e vivenciadas.

A todo momento, o poder nos questiona sobre a verdade. Por meio da relação poder/saber, somos submetidos à produção da verdade e só por meio da verdade produzida podemos exercer o poder, de forma que, para se estabel ecer uma relação de poder, é necessário que se tenha uma verdade regulamentada e institucional izada, o que per mite a transmissão e a reprodução dos efeitos do po$\operatorname{der}^{(7)}$

\section{CONST RUÇÃO DE PODER/ SABER POR MEIO DAS PRÁTICAS}

$\mathrm{N}$ a sociedade contemporânea, os diver sos regimes de práticas são materializados por meio de instituições como o sistema da saúde, o sistema educacional ou o sistema judiciário. É por meio dessa concretização institucional das práticas que se tornam possíveis a troca e a interconexão entre os vários regimes. $M$ as, mais do que isso, é por meio dessa troca que, por um lado, acontecerá a inovação ou a consolidação institucional e, de outro lado, com a necessidade dessa integração, condições serão criadas para tornar possíveis a fragmentação e a contestação das práticas próprias dos distintos regimes. Assim, as práticas de poder, instituídas nesses regimes, são vivenciadas e reconfiguradas pelas várias formas de conhecimento que definem seu objeto ${ }^{(8)}$.

As práticas que envolvem poder/ saber são 0 que as pessoas vivem cotidianamente e, em estruturas múltiplas e complexas, as práticas são cons- truídas, interagem, se sustentam e, às vezes, se contradizem. 0 conhecimento sempre ocorre nas práticas, de forma que, quando o conhecimento muda, as práticas também mudam. N esse sentido, o conhecimento é inseparável das práticas, assim como também é inseparável dos el ementos que as constituem: normas, fazeres e discursos. T anto o conhecimento quanto o poder emergem das práticas, 0 que evidencia a estreita relação entre ambos ${ }^{(9)}$.

Foucault estudou o poder usando como referencial a genealogia nietzschiana que busca compreender a constituição do sujeito consider ando seu contexto histórico. A geneal ogia deve ser compreendida como sendo orientada para o como do conhecimento, e é usada, tanto para explicar a existência de um conhecimento particular, como para entender suas transfor mações através das relações de poder e sua posição em um dispositivo político. $G$ eneal ogicamente, o poder não é considerado como uma realidade de essência definida ou portadora de características universais, mas como relações heterogêneas em constantes transfor mações ${ }^{(10)}$.

$N$ esse sentido, poder significa um aglomerado de relações maisoumenos organizado, hierarquizado e coordenado, responsável pelo delineamento e pela forma das situações vivenciadas no presente ${ }^{(11)}, 0$ que se aplica ao contexto das práticas de enfermagem, que não podem ser definidas de for ma homogênea; são moldadas e redesenhadas constantemente, de acordo com os elementos apresentados em cada situação em particular, considerando-se os el ementos envolvidos.

E ntretanto, no âmbito dessas relações, a possibilidade de reversão e de confrontamento entre adversários pode, a todo momento, criar lugares, tanto para o emprego de mecanismos de poder como de resistência. Com essa instabilidade, tanto o poder como a resistência podem ser analisados como el ementos que contribuem para um contexto de luta onde cada um mantém o foco em diferentes pontos da estrutura. Relações de poder arraigadas na intransigência se transformam em relações de dominação, muito mais do que em relações de poder propriamente ditas, uma vez que 0 poder sempre permite a possibilidade de resistên$\mathrm{Cia}^{(12)}$.

$\mathrm{N}$ esse sentido, pode-se compreender que, na perspectiva foucaultiana, o poder não existe em si próprio; é constituído nas relações e nas práticas vivenciadas cotidianamente. A noção de poder, em uma sociedade disciplinar, consiste na possibilida- 
de de se definirem identidades e ações, valores e nor mas, de acordo com as práticas e as estruturas em questão(10).

Assim, entende-se o poder como um mecanismo social sem que ocupe um lugar privilegiado nem exclusivo. Está disperso; embora, por vezes, de forma desigual, ao longo de todo o corpo social. É necessário compreender que, para o desenrolar de todo relacionamento, poder e resistência sempre caminham juntos, sem um ponto fixo na estrutura. Estão em constante movimento(10).

\section{CONSIDERAÇÕES FINAIS}

A compreensão das tensões próprias das práticas de enfermagem implica na busca de respostas a questionamentos que possam esclarecer como essas práticas são organizadas em determinado contexto. Para isso, há que se considerar que 0 conhecimento é inseparável das práticas, assim como também é inseparável dos elementos que as constituem - normas, fazeres e discursos.

Assim, a todo momento, em nossa prática cotidiana, o poder nos questiona sobre a verdade. Pela relação poder/ saber somos submetidos à produção da verdade e só por meio da verdade produzida podemos exercer o poder, de forma que, para se estabelecer uma relação de poder, é necessário que se tenha uma verdade regulamentada. N esse sentido, a busca pela valorização das práticas de enfermagem, no vasto cenário da atenção à saúde, requer que os profissionais invistam na busca de conhecimentos que subsidiem a prestação de uma assistência qualificada para o paciente e que, além disso, estejam dispostos a discutir o significado dessa assistência qualificada, de acordo com a realidade sócio-cultural da população atendida. É a atitude crítica diante de nossas práticas que deve nos mover na direção de uma reflexão sobre nosso entendimento acerca do significado dessas práticas, bem como das consequências dos posicionamentos e posturas assumidos em nosso exercício profissional.

\section{Endereço da autora / Dirección del autor / Author's address:}

I sabela Silva Câncio Velloso

Rua M aria H eilbuth Surette, 338, ap. 301, Buritis

30575-100, Belo H orizonte, M G

E-mail: isacancio@gmail.com

\section{REFERÊNCIAS}

1 Foucault M. Questions of method. In: Burchell G, Gordon C, M iller PM, editors. The Foucault effect: studies in governmental ity. London: H arvester; 1991. p. 73-86.

2 Foucault M. Politics and the study of discourse. In: Burchell G, Gordon C, M iller PM , editors. The Foucault effect: studies in governmentality. London: H arvester; 1991. p. 53-72.

3 Foucault M . Afterword: the subject and the power. In: Dreyfus $H$, Rabinow P. M ichel Foucault: beyond structuralism and her meneutics. Chicago: U niversity of Chicago Press; 1983. p. 208-26.

4 Rose N. Authority and the genealogy of subjectivity. In: H eelas $\mathrm{P}, \mathrm{L}$ ash $\mathrm{S}, \mathrm{M}$ orris $\mathrm{P}$, editors. D etraditionalization: critical reflections on authority and identity. Oxford: Blackwell; 1999. p. 294-327.

5 Rawlinson M C. Foucault's strategy: knowledge, power and the specificity of truth.J M ed Philos. 1987;12:371-95.

6 Kurcgant P, Ciampone M HT, M elleiro M M . 0 planejamento nas organizações de saúde: análise da visão sistêmica. Rev G aúcha Enferm. 2006;27(3):351-5.

7 F oucault M. Soberania e disciplina. In: M achado R, organizador. M icrofísica do poder. Rio de Janeiro: G raal; 2008. p. 179-91.

8 Basic concepts and themes. In: D ean M. G overnmentality: power and rule in modern society. L ondon: Sage; 1999. p. 9-39.

$9 \mathrm{M}$ ay T. T he philosophy of Foucault. M ontreal: M CGill-Q ueen's U niversity Press; 2006.

$10 \mathrm{M}$ achado R. Por uma arqueologia do poder. In: M achado R, organizador. M icrofísica do poder. Rio de Janeiro: G raal; 2008.

11 Foucault M. The confession of the Flesh. In: Gordon $C$, editor. Power/ knowledge: selected interviews and other writings. N ew Y ork: Pantheon; 1980. p. 194-228.

12 Foucault M . Discipline and punish: the birth of the prison. Vintage: N ew York; 1995.

Recebido em: 16/ 04/ 2010

A provado em: 30/ 05/ 2010 